\title{
Correction to: NSAID use and somatic exomic mutations in Barrett's esophagus
}

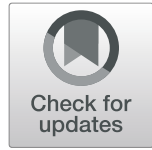

Patricia C. Galipeau', Kenji M. Oman', Thomas G. Paulson'1, Carissa A. Sanchez ${ }^{1}$, Qing Zhang², Jerry A. Marty ${ }^{3}$, Jeffrey J. Delrow ${ }^{4}$, Mary K. Kuhner ${ }^{5}$, Thomas L. Vaughan ${ }^{6}$, Brian J. Reid ${ }^{1,5,7}$ and Xiaohong Li ${ }^{\text {* }^{*}}$

\section{Correction to: Genome Med}

https://doi.org/10.1186/s13073-018-0520-y

It was highlighted that in the original article [1] the Availability of data and materials section was incorrect. This Correction article shows the revised Availability of data and materials section.

\section{Availability of data and materials}

The datasets generated during the current study are available in the database of Genotypes and Phenotypes (dbGaP) repository, study accession ID phs001654.v1.p1

\begin{abstract}
Author details
'Division of Human Biology, Fred Hutchinson Cancer Research Center, PO Box 19024, 1100 Fairview Ave N, Seattle, WA 98109-1024, USA.

${ }^{2}$ Bioinformatics Shared Resource, Fred Hutchinson Cancer Research Center, PO Box 19024, Seattle, WA 98109-1024, USA. ${ }^{3}$ Genomics Shared Resource, Fred Hutchinson Cancer Research Center, PO Box 19024, Seattle, WA 98109-1024, USA. ${ }^{4}$ Genomics and Bioinformatics Shared Resources, Fred Hutchinson Cancer Research Center, PO Box 19024, Seattle, WA 98109-1024, USA. ${ }^{5}$ Department of Genome Sciences, University of Washington, Foege Building S-250, Box 355065, 3720 15th Ave NE, Seattle, WA 98195-5065, USA. ${ }^{6}$ Department of Epidemiology, University of Washington, Division of Public Health Sciences, Fred Hutchinson Cancer Research Center, PO Box 19024, Seattle, WA 98109-1024, USA. 'Department of Medicine, University of Washington, Division of Human Biology, Fred Hutchinson Cancer Research Center, PO Box 19024, Seattle, WA 98109-1024, USA.
\end{abstract}

Received: 27 February 2019 Accepted: 27 February 2019

Published online: 12 March 2019

\section{Reference}

1. Galipeau, et al. NSAID use and somatic exomic mutations in Barrett's

esophagus. Genome Med. 2018;10:17. https://doi.org/10.1186/s13073-0180520-y.

\footnotetext{
* Correspondence: xili@fredhutch.org

${ }^{1}$ Division of Human Biology, Fred Hutchinson Cancer Research Center, PO Box 19024, 1100 Fairview Ave N, Seattle, WA 98109-1024, USA

Full list of author information is available at the end of the article
}

(c) The Author(s). 2019 Open Access This article is distributed under the terms of the Creative Commons Attribution 4.0 International License (http://creativecommons.org/licenses/by/4.0/), which permits unrestricted use, distribution, and reproduction in any medium, provided you give appropriate credit to the original author(s) and the source, provide a link to the Creative Commons license, and indicate if changes were made. The Creative Commons Public Domain Dedication waiver (http://creativecommons.org/publicdomain/zero/1.0/) applies to the data made available in this article, unless otherwise stated. 